\title{
Urinary Bladder Contractility: A Relationship with Central Nervous Activity and Sleep
}

\author{
Manoj G. Tyagi \\ Department of Pharmacology, Christian Medical College, Vellore, India
}

\section{Dear Editors,}

The urinary bladder has only two essential functions. It stores and periodically empties urine. Yet it is unique as a visceral organ, allowing integrated volitional and autonomous control of continence and voiding. Neuroanatomical, electrophysiological and pharmacological techniques have provided information about neural circuitry and the neurotransmitters involved in the neural control of voiding [1].

Storage of urine is dependent in part upon spinal reflex mechanisms that activate sympathetic and somatic pathways to the urethral outlet as well as tonic inhibitory systems in the brain that suppress the para sympathetic outflow. The central nervous regulation of the lower urinary tract is mediated by simple on-off switching circuits in the brain and spinal cord that are under voluntary control. The potential for central consequences of bladder contractility exists because neural circuits are present that communicate pelvic visceral status functions [2]. Barrington's nucleus (pontine micturition center) and Locus coeruleus are integral components of a circuit that performs this task [3]. These projections form the limb of the micturition reflex, in which Barrington's nucleus neurons are activated by bladder distention and in a response, initiate bladder contraction [4]. The same neurons from the Barrington's nucleus project to locus coeruleus, a major norepinephrine containing nucleus with divergent efferent projections that densely innervate the

\section{KARGER}

Fax +41613061234

E-Mail karger@karger.ch

www.karger.com
(C) 2008 S. Karger AG, Basel

1015-9770/08/0024-0217\$24.50/0

Accessible online at:

www.karger.com/cur forebrain [5]. The neurons from the Barrington's nucleus neurons also project to spinal preganglionic parasympathetic neurons, where they regulate activity of the bladder and other pelvic viscera.

A 'distended' hyperactive bladder can lead to anxiety and hyperarousal. On the other hand a voiding of 'distended' bladder would lead to central nervous depression. It is important to realize that voiding of distended bladder may lead to potentiation of sleep. Thus it seems pertinent to state that bladder distention may cause arousal and heightened central nervous system activity, while voiding of 'distended' bladder may cause central nervous depression and potentiation of sleep. This is mainly because locus coeruleus is also important in maintaining sleep and normal activity of the central nervous system and the GABAergic mechanisms may be involved in these actions [6, 7]. It seems likely that the bladder contribute to physiological homeostasis of the central nervous system. A role for ion channels like the potassium channels and hormones like corticotrophin releasing factor and vasopressin is possible [8]. Recent studies also suggest that the circuitry described earlier may also underlie the nicely documented comorbidity of certain psychiatric symptoms $[3,4]$. Thus it seems imperative to state that urinary bladder may play a facilitatory role in cognitive and behavioral functions [9]. These studies highlight the importance of urinary bladder in normal physiological role of maintaining central nervous activity and sleep. 


\section{References}

1 Roberts MM: Neurophysiology in neurourology. Muscle Nerve 2008;38:815-836.

$\checkmark 2$ Tyagi MG, Tripathi CD, Bapna JS, Stephen PM: Renal Denervation Blunts Centrally Administered Minoxidil Induced Attenuation of the Pressor Response to Vasopressin: Relationship to Adenylate Cyclase Activity. Pharmacol Commun 1996;7:115-124.

>3 Loewy AD, Saper CB, Baker RP: Descending projections from the pontine micturation center. Brain Res 1979;172:533-538.
4 de Groat WC, Booth AM, Yoshimura N: Neurophysiology of micturition and its modification in animal models of human disease; in: Maggi CA (ed): The autonomic nervous system. London, Harwood Academic, 1993, pp227-290.

5 Swanson LW, Hartman BK: The central adrenergic system. An immunoflourescence study of the location of cell bodies and their efferent connections in the rat utilizing dopamine-beta-hydroxylase as a marker. J Comp Neurol 1976;163:467-505.
6 Kaur S, Saxena RN, Mallick BN: GABA in locus coeruleus regulates spontaneous rapid eye movement sleep by acting on GABA receptors in freely moving rats. Neurosci Lett 1997;223:105-108.

7 Gonzalez MM, Debilly G, Valatx JL, Jouvet M: A novel role of locus coeruleus in sleep rebound mechanisms. Sleep Research 1995; $24 \mathrm{~A}$.

-8 Klausner AP, Steers WD: Corticotrophin releasing factor: a mediator of emotional influences on bladder function. J Urol 2004;172: 2570-2573.

-9 Rickenbacher E, Baez MA, Hale L, Leiser SC, Zderic SA, Valentino RJ: Impact of overactive bladder on the brain: central sequelae of a visceral pathology. Proc Natl Acad Sci USA 2008;105:10589-10594.

\section{Erratum}

Reference 11 should be replaced with 'Young HH: Conservative perineal prostatectomy: a presentation of new instruments and technic. JAMA 1908;41:999.' in the paper by Kirschner-Hermanns et al.: Do Patients with Urodynamically Proven Infravesical Obstruction and Detrusor Overactivity Have a Higher Risk for Long-Term Bothersome Symptoms after Brachytherapy in Comparison to Patients Treated with Radical Prostatectomy for Localized Prostate Cancer? Curr Urol 2008;2:135-141. 